\title{
Vision conditions among first-graders of different racial/ethnic groups a year after vision screening by school nurses in Southern California
}

\author{
Gergana Kodjebacheva ${ }^{* 1,2}$, Fei Yu ${ }^{2,3}$, Anne L. Coleman ${ }^{2,4}$ \\ ${ }^{1}$ Department of Public Health and Health Sciences, University of Michigan-Flint, Flint, MI, United States \\ ${ }^{2}$ Jules Stein Eye Institute and the Department of Ophthalmology, David Geffen School of Medicine, University of California at \\ Los Angeles, Los Angeles, United States \\ ${ }^{3}$ Department of Biostatistics, School of Public Health, University of California at Los Angeles, Los Angeles, United States \\ ${ }^{4}$ Department of Epidemiology, School of Public Health, University of California at Los Angeles, Los Angeles, United States
}

Received: July 13, 2015

DOI: $10.5430 /$ jnep.v6n2p27
Accepted: October 14, $2015 \quad$ Online Published: October 27, 2015

URL: http://dx.doi.org/10.5430/jnep.v6n2p27

\begin{abstract}
Background: Refractive error, if uncorrected, may decrease children's academic achievement. Pediatric amblyopia, if untreated, may lead to visual impairment. The aims were to determine the prevalence of vision conditions and untreated vision conditions during the first-grade, a year after mandated vision screening by nurses.

Methods: Ophthalmologists at the UCLA Mobile Eye Clinic (MEC) examined 2,286 first-graders located in Southern California. Myopia and hyperopia were defined as at least -0.75 dioptre (D) and $+1.25 \mathrm{Ds}$ in each principal meridian, respectively. Astigmatism was at least a 1-D difference between the two meridians. Untreated hyperopia was defined as habitual visual acuity worse than $20 / 30$ and the lack of eyeglasses for clinically meaningful refractive error, i.e. at least +3Ds in each principal meridian. Amblyopia was defined using a standard definition.

Results: In adjusted analysis, Asian/Pacific Islander children were more likely to have myopia compared to non-Hispanic White children. Forty-five out of 57 (78.9\%) children with clinically meaningful hyperopia lacked eyeglasses. The rates of untreated hyperopia were higher in Latino/African American children and in children attending Title I schools (i.e. schools disproportionately affected by poverty) compared to non-Hispanic white and children attending a non-Title I school, respectively. Seventeen of the 2,286 children (0.74\%) had amblyopia. Fourteen of the 17 children with amblyopia (82.4\%) were not receiving treatment for the condition at the time of the eye exam.

Conclusions: Since most children with vision conditions lack eyeglasses or treatment in the first-grade, interventions are needed to assist the school nurses in providing follow-up eye care to children.
\end{abstract}

Key Words: School vision screening, Nurses, Refractive error, Amblyopia, Academic development, Children

\section{INTRODUCTION}

Refractive errors and amblyopia, especially if left untreated, have negative consequences for children. Lack of eyeglasses for the treatment for refractive errors is the leading cause of visual impairment in children. ${ }^{[1-4]}$ Untreated amblyopia is associated with the development of visual impairment. ${ }^{[5]}$ Visual impairment may decrease the academic achievement of children, ${ }^{[6,7]}$ which is why the Department of Education

\footnotetext{
*Correspondence: Gergana Kodjebacheva; Email: gergana@umich.edu; Address: Department of Public Health and Health Sciences, University of Michigan-Flint, Flint, MI, United States.
} 
requires periodic vision screening in schools in most U.S. states. ${ }^{[8]}$ In California, nurses are mandated to offer vision screening to children in kindergarten in preparation for the first grade. If many children with vision conditions lack eyeglasses or treatment in the first-grade, a critical period of academic development, interventions are needed to assist the school nurses in providing eye care to children following the vision screening in kindergarten. Such interventions will help reap the benefits of the vision screening by nurses.

Gaps in the literature regarding children's refractive errors and amblyopia exist. Several prominent studies, however, have been conducted. For example, the National Health Interview Survey and the National Survey of Children with Special Health Care Needs used self-reported information to study children's unmet eye care needs (i.e. needing eyeglasses or vision care services but not receiving them). ${ }^{[9,10]}$ One study assessing the prevalence rates of refractive error in 2,523 children aged between 5 and 17 years in Latino, Asian, non-Hispanic White, and African American children in the U.S., examined the right eye of each child. ${ }^{[11]}$ Another study examined the prevalence of refractive error in non-Hispanic and African American preschool children. ${ }^{[12]}$ The Multi-Ethnic Pediatric Eye Disease Study (MEPEDS) presented findings on the prevalence of amblyopia in children of two racial/ethnic groups: African American and Hispanic children. ${ }^{[13]}$

In addition to the scarcity of information on the prevalence rates of myopia, hyperopia, astigmatism, and amblyopia in children of different racial/ethnic groups in the U.S., limited information is available on the racial/ethnic and school factors associated with the lack of treatment for clinically meaningful hyperopia, which if untreated, may decrease children's academic achievement. ${ }^{[7]}$ Hyperopia, especially if uncorrected, decreases reading ability in elementary school children and SAT scores in older children. ${ }^{[7]}$

Limited information is available on vision conditions in firstgraders as well. Younger children, such as first-graders, have different ocular characteristics compared to older children. ${ }^{[14]}$ The first grade is also a period when children become more dependent on their vision for academic activities. Academic achievement in the first-grade is a benchmark for long-term scholastic performance. ${ }^{[15]}$ Information on factors associated with untreated conditions in the first-grade may help develop interventions that correct vision conditions during this critical period of academic development. Given the gaps in the research, the present study focused both on the prevalence of vision conditions among American firstgraders of different racial/ethnic groups and the racial/ethnic and school factors associated with untreated conditions, es- pecially hyperopia. Interventions are also proposed to assist school nurses in providing follow-up eye care to children in first-graders.

\section{Methods}

\subsection{The Mobile Eye Clinic (MEC)}

The UCLA MEC has been providing vision care services in the Los Angeles area since 1975. ${ }^{[16,17]}$ The Clinic offered eye exams to all first-graders, whose parents/guardians consented, in four Title I and one non-Title I elementary schools from the Santa Monica Malibu Unified School District, over a six-year period between the 1999-2000 and 2005-2006 academic years. Title $\mathrm{I}$ is a federal designation indicating that children in the school are disproportionately affected by poverty. ${ }^{[18]}$

School nurses in the district sent invitations to all parents asking them to have children's eyes examined by ophthalmologists on the MEC. A total of 2,286 first-graders received eye examinations. These 2,286 first-graders accounted for $87 \%$ of all first-graders in the participating schools. The firstgraders in this study are representative of first-graders in the participating schools as well as children enrolled in public schools in California. The highest percentage of children both in our study and in the participating schools were Latino, followed by non-Hispanic White, Blacks/African American, and Asian/Pacific Islander. The racial/ethnic distribution of our first-graders is also similar to the distribution of children in public schools in California. Between 1999 and 2006, $33.6 \%$ of children in public schools in California were nonHispanic White compared to $30.2 \%$ in our study. Over the same time period, approximately $45 \%$ of children in public schools in California were Latino compared to $42.9 \%$ in our study. Approximately $8.2 \%$ of children in public schools in California were African American compared to $7.8 \%$ in our study ${ }^{[19]}$ We retrospectively analyzed data from the medical records of the 2,286 first-graders. The University of California, Los Angeles, Office for the Protection of Research Subjects approved the study.

\subsection{Eye examination}

Distance visual acuity testing was performed using the Snellen chart with and without eyeglasses as relevant. In illiterate children, distance visual acuity was ascertained using the E-game or Allen pictures. Using the Sloan chart in children with current glasses for reading or near work, if any, near visual acuity was assessed. Stereoacuity testing with the Titmus test was performed. Evaluation of extraocular muscle movements and alignment took place. Autorefraction was performed with the aid of the Retinomax and/or Humphrey autorefractors. A slit-lamp examination (external and fundus 
exams) and a refraction using the phoropter and BVAT II Video Acuity Tester were performed. The ophthalmologists performed cycloplegic refraction (i.e. dilation) in children who failed the initial vision screening.

\subsection{Main outcomes}

At least -0.75 dioptre (D) in each principal meridian and at least $+1.25 \mathrm{Ds}$ in each principal meridian defined myopia and hyperopia, respectively. ${ }^{[11]}$ Astigmatism was at least a 1-D difference between the two meridians. ${ }^{[1]}$ Untreated myopia or astigmatism was defined as the presence of habitual visual acuity worse than 20/30 and the lack of eyeglasses for the treatment of the condition on the day of the MEC eye exam. Poor visual acuity had to accompany the condition since not all children with refractive error have poor vision and need eyeglasses. The cut-off point of 20/30 was chosen to be consistent with the AAO Preferred Practice Patterns for referrals of children for evaluations by eye care specialists after the age of $5 ;^{[20]}$ in our study, the overwhelming majority of children were older than 5 years.

Untreated (i.e. uncorrected) hyperopia was defined as the presence of habitual visual acuity worse than 20/30 and the lack of eyeglasses for the treatment of hyperopia of at least $+3 \mathrm{D}$ in each principal meridian on the day of the MEC eye exam. At least $+3 \mathrm{D}$ was used as a cut-off for defining untreated hyperopia because most other hyperopic children do not need eyeglasses. ${ }^{[12]}$ The presence of unilateral or bilateral amblyopia was determined. Unilateral amblyopia was classified as $\mathrm{a} \geq 2$ line interocular difference in best habitual visual acuity, with visual acuity 20/30 or worse in the worse eye where a unilateral amblyogenic factor in the affected eye was present. ${ }^{[21]}$ Bilateral amblyopia was defined as reduced best-corrected visual acuity worse than 20/40 in both eyes in the presence of a bilateral amblyogenic factor. ${ }^{[21]}$ Unilateral and bilateral amblyogenic factors were defined as in the MEPEDS. ${ }^{[21]}$

\subsection{Risk factors}

Potential risk factors included age, gender, race/ethnicity (non-Hispanic White, Latino, Black/African American, Asian/Pacific Islander, and Other children), type of school, and academic year. Parents self-reported the race/ethnicity of children. Children in the "other" category were those of other racial/ethnic groups or mixed races/ethnicities.

\subsection{Statistical analysis}

Using SPSS 16.0, we calculated the overall and race/ethnicity-specific rates of myopia, hyperopia, astigmatism, and amblyopia. Logistic regression models, adjusted for school, age, gender, and year, showed the likelihood of having refractive errors in Latino, Black/African, Asian/Pacific Islander, and Other children compared to nonPublished by Sciedu Press
Hispanic White children. The prevalence rates of untreated myopia, hyperopia, astigmatism, and amblyopia were calculated. The Pearson chi square test helped determine differences in untreated hyperopia by race/ethnicity and school. Significance was defined as $p<.05$.

\section{RESULTS}

Among the 2,286 first-graders, most were 6-year old. Most were Latinos and non-Hispanic Whites (see Table 1). Most were from Title I schools. A total of 264 (out of 2,286 or $11.5 \%$ ) had refractive errors. The prevalence rates of myopia, hyperopia, and astigmatism were $4.9 \%, 4.6 \%$, and $6.5 \%$, respectively (see Table 2). Asian/Pacific Islander children had higher rates of myopia than hyperopia or astigmatism.

Table 1. Summary of demographic characteristics of first-graders $(n=2,286)$

\begin{tabular}{lll}
\hline Characteristic & Number of children & \% \\
\hline Age & & \\
5-year olds & 47 & 2.1 \\
6-year olds & 1,325 & 58.0 \\
7-year olds & 914 & 40.0 \\
Gender & & \\
Male & 1,185 & 51.8 \\
Female & 1,101 & 48.2 \\
Race/ethnicity & & \\
Non-Hispanic White & 691 & 30.2 \\
Latino & 980 & 42.9 \\
Black/African American & 179 & 7.8 \\
Asian/Pacific Islander & 146 & 6.4 \\
Other race/ethnicity & 290 & 12.7 \\
Year of eye exam & & 16.8 \\
2000-2001 & 376 & 16.4 \\
2001-2002 & 402 & 26.5 \\
2002-2003 & 377 & \\
2003-2004 & 398 & 16.5 \\
2004-2005 & 605 & \\
2005-2006 & & \\
Type of school & 350 & 17.5 \\
Children in Title I schools & & \\
Children in a Non-Title I school & & \\
\hline & & \\
\hline
\end{tabular}

When controlling for age, gender, school, and academic year, Latino, African American, Asian/Pacific Islander children were more likely to have myopia compared to non-Hispanic White children (see Table 3). Asian/Pacific Islander children experienced lower odds of having hyperopia compared to non-Hispanic White children in adjusted analyses (see Table 3). In adjusted analyses, Latino and African American children had increased odds of having astigmatism compared to non-Hispanic White children (see Table 3). In adjusted analyses, no differences in the presence of any refractive error by school were evident (results not shown). 
Table 2. Prevalence of myopia, hyperopia, and astigmatism by race/ethnicity

\begin{tabular}{llll}
\hline Race/ethnicity & Myopia N (\%) & Hyperopia N (\%) & Astigmatism N (\%) \\
\hline Overall, $\mathrm{n}=2,286$ & $111(4.9 \%)$ & $106(4.6 \%)$ & $149(6.5 \%)$ \\
Non-Hispanic White, $\mathrm{n}=691$ & $14(2.0 \%)$ & $38(5.5 \%)$ & $21(3.0 \%)$ \\
Latino, $\mathrm{n}=980$ & $60(6.1 \%)$ & $42(4.3 \%)$ & $88(9.0 \%)$ \\
Black/African American, $\mathrm{n}=179$ & $10(5.6 \%)$ & $11(6.1 \%)$ & $15(8.4 \%)$ \\
Asian/Pacific Islander, $\mathrm{n}=146$ & $12(8.2 \%)$ & $2(1.4 \%)$ & $7(4.8 \%)$ \\
Other, $\mathrm{n}=290$ & $15(5.2 \%)$ & $13(4.5 \%)$ & $18(6.2 \%)$ \\
\hline
\end{tabular}

Table 3. The likelihood of having myopia, hyperopia, and astigmatism by race/ethnicity* $(\mathrm{n}=2,286)$

\begin{tabular}{|c|c|c|c|}
\hline Risk Factors & \multirow{2}{*}{ Myopia } & \multirow{2}{*}{ Hyperopia } & \multirow[t]{2}{*}{ Astigmatism } \\
\hline Race/ethnicity & & & \\
\hline \multirow{3}{*}{ Latino vs. non-Hispanic White } & $\mathrm{OR}=3.375$ & $\mathrm{OR}=0.838$ & $\mathrm{OR}=3.031$ \\
\hline & 95\% CI: $1.847-6.168$ & 95\% CI: 0.527-1.334 & 95\% CI: $1.841-4.991$ \\
\hline & $P<.001$ & $P=.457$ & $P<.001$ \\
\hline \multirow{3}{*}{ Black/African American vs. non-Hispanic White } & $\mathrm{OR}=3.012$ & $\mathrm{OR}=1.202$ & $\mathrm{OR}=2.929$ \\
\hline & 95\% CI: 1.307-6.939 & 95\% CI: 0.597-2.418 & 95\% CI: $1.468-5.845$ \\
\hline & $P=.010$ & $P=.607$ & $P=.002$ \\
\hline \multirow{3}{*}{ Asian/Pacific Islander vs. non-Hispanic White } & $\mathrm{OR}=4.239$ & $\mathrm{OR}=0.222$ & $\mathrm{OR}=1.564$ \\
\hline & 95\% CI: $1.913-9.395$ & 95\% CI: 0.053-0.935 & 95\% CI: 0.649-3.765 \\
\hline & $P<.001$ & $P=.040$ & $P=.319$ \\
\hline \multirow{3}{*}{ Other vs. non-Hispanic White } & $\mathrm{OR}=2.587$ & $\mathrm{OR}=0.791$ & $\mathrm{OR}=1.973$ \\
\hline & 95\% CI: $1.228-5.449$ & 95\% CI: 0.413-1.515 & 95\% CI: $1.030-3.777$ \\
\hline & $P=.012$ & $P=.480$ & $P=.040$ \\
\hline
\end{tabular}

Note. OR = Odds ratio, CI = Confidence interval; *Results based on logistic regression models assessing the likelihood of having myopia, hyperopia, or astigmatism among all children, adjusting for school, age, gender, and academic year.

The majority of children with myopia, hyperopia, and astigmatism, had poor visual acuity (see Table 4). All children with myopia and astigmatism accompanied by poor visual acuity, except for one child, had no eyeglasses. The overwhelming majority of children with hyperopia had their condition untreated (see Table 4). The rates of untreated hy- peropia were higher in Latino/African American children and in children attending Title I schools compared to nonHispanic white and children attending a non-Title I school, respectively; these results were not statistically significant (see Table 5).

Table 4. Clinically meaningful refractive error and untreated refractive error

\begin{tabular}{lll}
\hline $\begin{array}{l}\text { Refractive } \\
\text { error }\end{array}$ & $\begin{array}{l}\text { Percentage of children with clinically meaningful } \\
\text { refractive error (out of those with any refractive error) }\end{array}$ & $\begin{array}{l}\text { Percentage of children with untreated refractive error } \\
\text { (out of those with clinically meaningful refractive error) }\end{array}$ \\
\hline \multirow{2}{*}{ Myopia } & $65.8 \%$ & $100 \%$ \\
& $(73$ of 111$)$ & $(73$ of 73$)$ \\
\multirow{2}{*}{ Hyperopia } & $53.8 \%$ & $78.9 \%$ \\
& $(57$ of 106$)$ & $(45$ of 57$)$ \\
\multirow{2}{*}{ Astigmatism } & $69.1 \%$ & $99.0 \%$ \\
& $(103$ of 149$)$ & $(102$ of 103$)$ \\
\hline
\end{tabular}

Seventeen of the 2,286 children $(0.74 \%)$ had either unilateral or bilateral amblyopia. Four of the 2,286 $(0.17 \%)$ had bilateral amblyopia and 13 out of 2,286 $(0.57 \%)$ had unilateral amblyopia. Among the 17 children with amblyopia, 3 were non-Hispanic whites, 6 were Latino, 3 were African American, none were Asian/Pacific Islander, and 5 were of another race/ethnicity or did not report their ethnicity; the prevalence rates were, $0.4 \%, 0.6 \%, 1.7 \%, 0 \%, 1.7 \%$, in non-Hispanic White, Latino, African American, Asian/Pacific Islander, and Other children, correspondingly. Fourteen of the 17 children with amblyopia (82.4\%) were not receiving treatment for the condition at the time of the MEC eye exam. 
Table 5. Untreated hyperopia by race/ethnicity and school $(\mathrm{n}=57)$

\begin{tabular}{ll}
\hline Risk Factors & Percentage of children with untreated hyperopia \\
\hline Race/ethnicity* & \\
Non-Hispanic White & $66.7 \%(14$ of 21$)$ \\
Latino & $88.0 \%(22$ of 25$)$ \\
Black/African American & $100 \%$ (5 of 5$)$ \\
Other & 66.7 (4 of 6$)$ \\
$p$-value & .171 \\
Type of school & \\
Title I schools & $82.6 \%(38$ of 46$)$ \\
Not a title I school & 63.6 (7 of 11$)$ \\
$p$-value & .166 \\
\hline
\end{tabular}

*No Asian/Pacific Islander first-grader had clinically meaningful hyperopia

\section{Discussion}

We cannot reap the benefits of vision screening by nurses in kindergarten if children do not receive treatment and do not wear eyeglasses in the first grade. Reasons why children may not receive eyeglasses and other treatment following the vision screening by nurses include parental disbelief the child needs eye care as well as financial and transportation barriers to eye care. ${ }^{[17]}$ In addition, children may dislike, break, or lose their eyeglasses. ${ }^{[17]}$

After statistical adjustment, the prevalence rates of refractive error differed by race/ethnicity. While the rates of myopia in our study were lower than those in the Collaborative Longi- tudinal Evaluation of Ethnicity and Refractive Error Study by Kleinstein et al., ${ }^{[11]}$ which included primarily older children, our finding of lowest rates of myopia in non-Hispanic whites and highest rates in Asians/Pacific Islanders is consistent with their results (see Table 6). In both studies, Latinos had the highest rates of astigmatism compared to children of other racial/ethnic groups. Another consistent finding is that the lowest prevalence of hyperopia among racial/ethnic groups was in Asians/Pacific Islanders. ${ }^{[11]}$ Both in other research and our study, ${ }^{[8,22]}$ non-Hispanic Whites tended to have higher rates of hyperopia compared to Asians/Pacific Islanders.

Table 6. Comparison of the prevalence rates of any refractive errors by race/ethnicity among the present study that includes 5 to 7 year old children, that by Kleinstein et al., Refractive Error and Ethnicity in Children, 2003, that includes children aged 5 to 17, and that by Giordano et al., 2009, Prevalence of Refractive Error among Preschool Children in an Urban Population, that included 6-year old children, using the same or similar definitions

\begin{tabular}{|c|c|c|c|c|c|c|c|}
\hline & \multicolumn{3}{|l|}{ Myopia } & \multicolumn{2}{|c|}{ Hyperopia } & \multicolumn{2}{|c|}{ Astigmatism } \\
\hline & $\begin{array}{l}\text { Present } \\
\text { study }\end{array}$ & $\begin{array}{l}\text { Kleinstein } \\
\text { et al., } 2003\end{array}$ & $\begin{array}{l}\text { Giordano } \\
\text { et al., } 2009\end{array}$ & $\begin{array}{l}\text { Present } \\
\text { study }\end{array}$ & $\begin{array}{l}\text { Kleinstein } \\
\text { et al., } 2003\end{array}$ & $\begin{array}{l}\text { Present } \\
\text { study }\end{array}$ & $\begin{array}{l}\text { Kleinstein } \\
\text { et al., } 2003\end{array}$ \\
\hline & $\begin{array}{l}\text { First- } \\
\text { graders }\end{array}$ & $\begin{array}{l}\text { Children aged } \\
5 \text { to } 17 \text { years }\end{array}$ & $\begin{array}{l}\text { Six-year old } \\
\text { children }\end{array}$ & $\begin{array}{l}\text { First- } \\
\text { graders }\end{array}$ & $\begin{array}{l}\text { Children aged } 5 \\
\text { to } 17 \text { years }\end{array}$ & $\begin{array}{l}\text { First- } \\
\text { graders }\end{array}$ & $\begin{array}{l}\text { Children aged } \\
5 \text { to } 17 \text { years }\end{array}$ \\
\hline $\begin{array}{l}\text { Definition of } \\
\text { condition }\end{array}$ & $\begin{array}{l}\text { At least } \\
-0.75 D\end{array}$ & $\begin{array}{l}\text { At least } \\
-0.75 D\end{array}$ & $\begin{array}{l}\text { At least } \\
-1 D\end{array}$ & $\begin{array}{l}\text { At least } \\
+1.25 D\end{array}$ & $\begin{array}{l}\text { At least } \\
+1.25 D\end{array}$ & $\begin{array}{l}\text { At least } \\
1 D\end{array}$ & $\begin{array}{l}\text { At least } \\
1 D\end{array}$ \\
\hline $\begin{array}{l}\text { Non-Hispanic } \\
\text { White }\end{array}$ & $2.0 \%$ & $4.4 \%$ & $1.2 \%$ & $5.5 \%$ & $19.3 \%$ & $3.0 \%$ & $26.4 \%$ \\
\hline Latino & $6.1 \%$ & $13.2 \%$ & - & $4.3 \%$ & $12.7 \%$ & $9.0 \%$ & $36.9 \%$ \\
\hline $\begin{array}{l}\text { Black/African } \\
\text { American }\end{array}$ & $5.6 \%$ & $6.6 \%$ & $6.6 \%$ & $6.1 \%$ & $6.4 \%$ & $8.4 \%$ & $20.0 \%$ \\
\hline $\begin{array}{l}\text { Asian/Pacific } \\
\text { Islander }\end{array}$ & $8.2 \%$ & $18.5 \%$ & - & $1.4 \%$ & $6.3 \%$ & $4.8 \%$ & $33.6 \%$ \\
\hline
\end{tabular}

We estimated both the prevalence of refractive errors and the prevalence of untreated refractive errors. The high rate of uncorrected refractive error in first-graders in this study is consistent with the findings of older children in prior research. ${ }^{[23]}$ In addition, in the National Health and Nutrition Examination Survey, African American or Latino adoles- 
cents aged 12 to 18 years were less likely to own eyeglasses compared to non-Latino White children. ${ }^{[24]}$ In the National Survey of Children with Special Health Care Needs, using self-reported data, African American and Latino children younger than 18 years were twice as likely to need eyeglasses or vision care services but not receiving them compared nonLatino White children. ${ }^{[9]}$ Through the use of self-reported data, the National Health Interview Survey found that uninsured and poor children aged 18 years and younger had an increased likelihood of needing eye care but not receiving it compared to insured and non-poor children. ${ }^{[10]}$

A higher percentage of children had untreated hyperopia in the Title I schools compared to non-Title I school. One potential reason may be the lower socioeconomic status of Title I schools. Lacking insurance and living in poverty have been linked to not receiving vision care in children. ${ }^{[25]}$ Overall, the rates of uncorrected hyperopia were high in all participating schools. The finding suggests the need for eye care interventions in public schools.

The prevalence of amblyopia in this study of primarily 6 years old children $(0.6 \%)$ and the study of 6 -year old Australian children ${ }^{[26]}$ with a prevalence of $0.7 \%$ was very similar. The prevalence rates of amblyopia in African American children in our study (1.7\% in 5-7 years old children) and in the MEPEDS ( $1.3 \%$ in 6 year old children) were similar. ${ }^{[13]}$ The prevalence in Latino children in our study (0.6\% in 5-7 years old children) was lower than in the MEPEDS (3\% in 6 year old children). ${ }^{[13]}$ The MEPEDS primarily included participants from Inglewood, a less affluent community than Santa Monica. In the MEPEDS, none of the children with amblyopia were previously diagnosed ${ }^{[27]}$ while in our study, $17.6 \%$ of the children with amblyopia were treated. Poverty may be a reason for the higher rates of amblyopia among Latinos in MEPEDS. Poor children with amblyopia were more likely to have visual acuity $20 / 70$ or worse compared to non-poor children in one study. ${ }^{[28]}$

One limitation of our study is that the UCLA MEC has no information on the reasons for the refusal to participate. Some of the parents refusing for their child to participate may have already taken their child for eye treatment, thus overestimating the overall rates of untreated conditions in the schools in our study. Other parents may believe that their child does not need eye exams, ${ }^{[25]}$ thus underestimating the rates of untreated conditions in our study. There should be no bias in the participation of subjects in our study, however, because of the similar racial/ethnic distribution of the first-graders in our study compared to the children in public schools in California. The difference in the rates of untreated hyperopia between Title I schools and the non-Title school was not statistically significant, which may be because of the smaller number of children in the non-Title I school. The study cannot make definite conclusions about the differences in untreated conditions in non-Title and Title I schools since only one non-Title I school was visited. Still, a significant number of 605 first-graders were from the non-Title I school. All regression analyses were adjusted for type of school. The strengths of our study include the high participation rate, the large sample of first-graders, a sample representative of children in the school district and California public schools, and the assessment of differences in conditions by race/ethnicity and school.

The findings of the study suggest the need for eye care interventions in both Title I and non-Title schools and among children of different racial/ethnic groups. In most U.S. states, school nurses are mandated to provide vision screening and refer children who fail the vision screening to eye care professionals for follow-up care. Interventions should assist nurses in screening for visual impairment, offering education on the importance of wearing eyeglasses, and monitoring the use of eyeglasses in the classroom. There are several examples of school-based eye care interventions that may promote the receipt of eyeglasses and education on the importance of wearing eyeglasses in schools. The Healthy Start Program, funded by the California Department of Education, provides vision screening to reduce the unmet need for vision care in the state. ${ }^{[29]}$ ChildSight $^{[30]}$ and the UCLA Mobile Eye Clinic $^{[31]}$ are community programs that partner with schools to offer eye exams and eyeglasses to children. The Vision In-School and Community-Insight programs provide vision education to elementary students. ${ }^{[31]}$ Prior research found that providing eye exams and one pair of eyeglasses were not sufficient in ensuring that children wear eyeglasses. Children need two pairs of attractive eyeglasses; one should be kept at home and another in the classroom. ${ }^{[17]}$ Children also need daily reminders by teachers to use their eyeglasses. ${ }^{[17]}$ Nurses cannot offer such comprehensive eye care alone; they need to collaboration of the school administrators, teachers, and the community.

Today's first-graders are future high school and college students. Interventions early in life have the potential of addressing health concerns in the long run. ${ }^{[32]}$ School-based programs offering eye exams following nurses' vision screenings may help decrease parental barriers to taking their children to the eye doctor. ${ }^{[33]}$ Interventions offering more than eye exams such as two pairs of attractive eyeglasses, education for parents on how to encourage their children to wear their eyeglasses at home, and monitoring of the use of eyeglasses in the classroom, may be especially successful in improving children's vision. A preventative eye care mes- 
sage, similar to that for dental care, needs to be developed in schools and society. ${ }^{[34,35]}$ Such a message may promote the academic achievement of both children and schools. It may also promote college completion and better careers as children and adolescents transition into adulthood.

\section{CONFLicts OF INTEREST Disclosure}

The authors declare that they have no competing interests.

\section{REFERENCES}

[1] Holden BA. Uncorrected refractive error: the major and most easily avoidable cause of vision loss. Community Eye Health. 2007; 20(63): 37-39.

[2] Vitale S, Cotch MF, Sperduto RD. Prevalence of visual impairment in the United States. Journal of the American Medical Association. 2006; 295(18); 2158-63.

[3] Maul E, Barroso S, Munoz SR, et al. Refractive error study in children: Results from la Florida, Chile. American Journal of Ophthalmology. 2000; 129(4): 445-454. http://dx.doi.org/10.1016 /S0002-9394 (99) 00454-7

[4] Robaei D, Rose K, Ojaimi E, et al. Visual acuity and the causes of visual loss in a population-based sample of 6-year-old Australian children. Ophthalmology. 2005; 112(7): 1275-1282. http: //dx.doi.org/10.1016/j.ophtha. 2005.01.052

[5] Chua B, Mitchell P. Consequences of amblyopia on education, occupation, and long term vision loss. British Journal of Ophthalmology. 2004; 88(9): 1119-1121. http://dx.doi.org/10.1136/bjo.2 004.041863

[6] Kulp MT, Schmidt PP. Visual predictors of reading performance in kindergarten and first grade children. Optometry and Visual Science. 1996; 73(4): 255-262. http://dx.doi.org/10.1097/0000632 4-199604000-00007

[7] Rosner J. The relationship between moderate hyperopia and academic achievement: How much plus is enough? Journal of American Optometry Association. 1997; 68(10): 648-650.

[8] Prevent Blindness America. State Mandated School Eye Exam and Vision Screening Laws. Available from: http://nationalcenter.preventblindness.org/model-s tate-school-entry-vision-screening-legislation

[9] Heslin KC, Casey R, Shaheen MA, et al. Racial and ethnic differences in unmet need for vision care among children with special health care needs. Archives of Ophthalmology. 2006; 124(6): 895902. http://dx.doi.org/10.1001/archopht.124.6.895

[10] Newacheck PW, Hughes DC, Hung Y, et al. The unmet health need of America's children. Pediatrics. 2000; 105(4): 989-997.

[11] Collaborative Longitudinal Evaluation of Ethnicity and Refractive Error Study Group. Refractive error and ethnicity in children. Archives of Ophthalmology. 2003; 121: 1141-47.

[12] Giordano L, Friedman DS, Repka MX, et al. Prevalence of refractive error among preschool children in an urban population: The Baltimore pediatric eye disease study. Ophthalmology. 2009; 116(4): 739746. http://dx.doi.org/10.1016/j.ophtha.2008.12.030

[13] Kleinstein RN, Jones LA, Hullett S, et al. Prevalence of amblyopia and strabismus in African American and Hispanic children ages 6 to 72 months: The multi-ethnic pediatric eye disease study. Ophthalmology. 2008; 115(7): 1229-1236. http://dx.doi.org/10.1016 /j.ophtha.2007.08.001

[14] Cotlier E, Weinreb R. Early refractive development in humans. Survey of Ophthalmology. 1995; 40(3): 207-216. http://dx.doi.o $\mathrm{rg} / 10.1016 / \mathrm{S} 0039-6257$ (95) 80027-1

Published by Sciedu Press
[15] Alexander K, Entwisle D, Horsey CS. From first grade forward: Early foundations of high school dropout. Sociology of Education. 1997; 70(2): 87-107. http://dx.doi .org/10.2307/2673158

[16] Fischbach LA, Lee DA, Englehardt RF, et al. The prevalence of ocular disorders among Hispanic and Caucasian children screened by the UCLA mobile eye clinic. Journal of Community Health. 1993; 18(4): 201-211. http://dx.doi.org/10.1007/BF01324431

[17] Kodjebacheva G, Maliski S, Yu F, et al. Decreasing uncorrected refractive error in the classroom through a multifactorial pilot intervention. The Journal of School Nursing. 2014; 30(1): 24-30. http://dx.doi.org/10.1177/1059840513486009

[18] U.S. Department of Education. Improving Basic Programs Operated by Local Educational Agencies (Title I, Part A). Washington, D.C.: U.S. Department of Education. Available from: http: //www2.ed.gov/programs/titleiparta/index.html

[19] California Department of Education Statistics. DataQuest. Sacramento, CA: California Department of Education. Available from: http://dq.cde.ca.gov/dataquest

[20] AAO Preferred Practice Patterns. Pediatric Eye Evaluations Screening and comprehensive ophthalmic evaluation. Washington D.C.: AAO Preferred Practice Patterns. Available from: http://one.aao.org/preferred-practice-pattern /pediatric-eye-evaluations-ppp--september-2012

[21] Varma R, Deneen J, Cotter S, et al. The multi-ethnic pediatric eye disease study: Design and methods. Ophthalmic Epidemiology. 2006; 13(4): 253-262. PMid:16877284

[22] The Eye Diseases Prevalence Research Group. The prevalence of refractive errors among adults in the United States, western Europe, and Australia. Archives of Ophthalmology. 2004; 122(4): 495-505. http://dx.doi.org/10.1001/archopht.122.4.495

[23] Pizzarello L, Tilp M, Tiezzi L, et al. A new school-based program to provide eyeglasses: ChildSight. Journal of American Association for Pediatric Ophthalmology and Strabismus. 1998; 2(6): 372-375. http://dx.doi .org/10.1016/S1091-8531 (98) 90038-6

[24] Kemper A, Gurney J, Eibschitz-Tsimhoni M, et al. Corrective lens wear among adolescents: Findings from the national health and nutrition examination survey. Journal of Pediatric Ophthalmology and Strabismus. 2007; 44(6): 356-362.

[25] Kimel LS. Lack of follow-up exams after failed school vision screenings: An investigation of contributing factors. The Journal of School Nursing. 2006; 22(3): 156-162.

[26] Robaei D, Rose KA, Ojaimi E, et al. Causes and associations of amblyopia in a population-based sample of 6-year-old Australian children. Archives of Ophthalmology. 2006; 124(6): 878-884. http: //dx.doi.org/10.1001/archopht.124.6.878

[27] Tarczy-Hornoch K. Prevalence of amblyopia and strabismus in African-American and Hispanic children. Master's thesis. Los Angeles, CA: University of Southern California. 2007. Available from: http://digitallibrary.usc.edu/cdm/ref/collect ion/p15799coll127/id/556801

[28] Hudak D, Magoon E. Poverty predicts amblyopia treatment failure. Journal of AAPOS. 1997; 1: 214-215. 
[29] California Department of Education. Healthy Start program. Sacramento, CA: California Department of Education. Available from: http://www.cde.ca.gov/sp/cd/re/chssco.asp

[30] Helen Keller International. ChildSight. Available from: http://www.hki.org/our-work/helping-people-see /childsight\#.ViLtwqSCnSw

[31] Jules Stein Eye Institute. Community Outreach. Las Angeles, CA: Jules Stein Eye Institute. Available from: http://www.jsei.org /About/about_comm.htm

[32] Wadsworth M. Health inequalities in the life course perspective. Social Science and Medicine. 1997; 44(6): 859-869. http://dx.doi .org/10.1016/S0277-9536(96)00187-6
[33] Kodjebacheva G, Brown ER, Estrada L, et al. Uncorrected refractive error among first-grade students of different racial/ethnic groups in southern California: results a year after school-mandated vision screening. Journal of Public Health Management and Practice. 2011; 17(6): 499-505. PMid:21964359

[34] Coleman AL, Kodjebacheva G, Wallace SP, et al. Visual functioning of individuals and communities: A Conceptual framework. Clinical Medicine: Geriatrics. 2008; 2: 13-20.

[35] Kodjebacheva GD, Maliski S, Coleman AL. Use of eyeglasses among children in elementary school: perceptions, behaviors, and interventions discussed by parents, school nurses, and teachers during focus groups. American Journal of Health Promotion. 2015; 29(5): 324331. PMid:24717070 http://dx.doi .org/10.4278/ajhp. 1203 15-QUAL-140 